\title{
A Deoxyribozyme-Initiated Self-Catalytic DNA Machine for Amplified Live-Cell Imaging of MicroRNA
}

Yeqing Wan, Gaiping Li, Lina Zou, Hong Wang, Qing Wang, Kaiyue Tan, Xiaoqing Liu and Fuan Wang*

College of Chemistry and Molecular Sciences, Wuhan University, Wuhan, 430072, P. R. China

* To whom correspondence should be addressed.

Fax: (+) 86-27-68756307;

Tel: (+) 86-27-68756307;

E-mail: fuanwang@whu.edu.cn 


\section{Supporting Information}

\section{Table of Contents}

Table S1. The DNA sequences used to establish the SDA system..... S3

Table S2. The mutant sequences of miR-21 S4

Table S3. Comparison of different enzyme-free methods for microRNA detection. S5

Figure S1. Schematic illustration of the CSA reaction S6

Figure S2. Optimization of $\mathrm{H}_{2}$ S7

Figure S3. Optimization of the reaction buffer S8

Figure S4. Optimization of the reaction temperature S9

Figure S5. Optimization of the substrate to the blocker $\left(\mathrm{S}_{1} / \mathrm{L}\right)$ ratio S10

Figure S6. Sensitivity of the n-SDA system S11

Figure S7. Selectivity of the SDA system

Figure S8. Schematic illustration of updated miR-21-targeting system S13

Figure S9. Optimization of the auxiliary hairpin probe S14

Figure S10. Specificity of updated miR-21-targeting system S15

Figure S11. Performance of the SDA system in serum samples S16

Figure S12. Incubation time optimization for intracellular miR-21 imaging S17

Figure S13. Flow cytometry of MCF-7 cells treated with two sensing systems S18

References S19 


\section{Supporting Information}

Table S1. The DNA sequences used to establish the SDA sensing system

\begin{tabular}{|c|c|}
\hline Name & Sequence(5'---3') \\
\hline $\mathbf{H}_{1}$ & 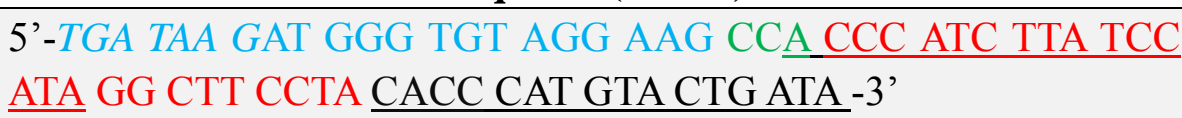 \\
\hline $\mathbf{H}_{2}\left(\mathbf{H}_{2 a}\right)$ & $\begin{array}{c}\text { '-GGT AAC AGC GAT TAGG AA GCC TAT GGA TAAGAT GGG } \\
\underline{\text { CTC TAC ACC CAT CTA TCC ATA GGC ACC CAT GTA CAG }} \\
\underline{\text { TC-3' }}\end{array}$ \\
\hline $\mathbf{H}_{3}$ & 5'-TCA TTC AGC GAT CCT AT GGA TAA G ATG GGT GTA GAG \\
\hline $\mathbf{H}_{2 \mathbf{b}}$ & $\begin{array}{c}\text { 5'-GGT AAC AGC GAT TAGG AA GCC TAT GGA TAAGAT GGG } \\
\text { CTCT ACACC GATC TTA TCC A TAGGC ACC CAT GTA CAG } \\
\text { TC-3' }\end{array}$ \\
\hline $\mathbf{H}_{2 \mathrm{c}}$ & $\begin{array}{c}\text { 5'-GGT AAC AGC GAT TAGG AA GCC TAT GGA TAAGAT GGG } \\
\text { CTCT ACACC CATC TTA TCC A TAGGC ACC CAT GTA CAG } \\
\text { TC-3' }\end{array}$ \\
\hline $\mathbf{H}_{\mathrm{P}}$ & $\begin{array}{c}\text { 5'-TCA GAC TGA TGT TGA TGC TTC CTA CAC CCA TCT TAT } \\
\text { CAT CAA CAT CAG TCT GAT AAG CTA-3' }\end{array}$ \\
\hline $\mathrm{S}_{1}$ & 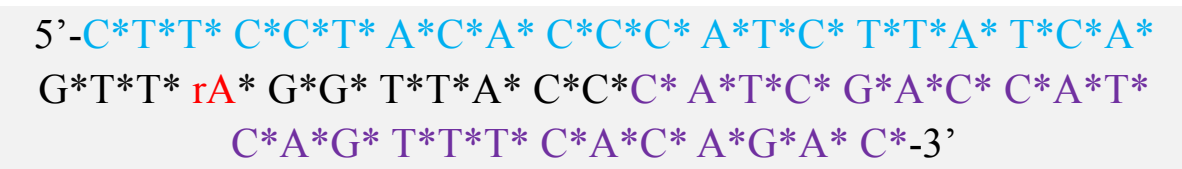 \\
\hline $\mathbf{L}$ & $\begin{array}{l}\text { 5'-GTC TGT GAA ACT GAT GGT CGA TGT TTT TAG ATG CGT } \\
\text { GTA GGA AG -3' }\end{array}$ \\
\hline $\mathbf{S}_{3}$ & $\begin{array}{c}\text { 5' }^{\prime} \mathrm{C}^{*} \mathrm{~T}^{*} \mathrm{~T}^{*} \mathrm{C}^{*} \mathrm{C}^{*} \mathrm{~T}^{*} \mathrm{~A}^{*} \mathrm{C}^{*} \mathrm{~A}^{*} \mathrm{C}^{*} \mathrm{C}^{*} \mathrm{C}^{*} \mathrm{~A}^{*} \mathrm{~T}^{*} \mathrm{C}^{*} \mathrm{~T}^{*} \mathrm{~T}^{*} \mathrm{~A}^{*} \mathrm{~T}^{*} \mathrm{C}^{*} \mathrm{~A}^{*} \\
\mathrm{G}^{*} \mathrm{~T}^{*} \mathrm{~T}^{*} \mathrm{~A}^{*} \mathrm{G}^{*} \mathrm{G}^{*} \mathrm{~T}^{*} \mathrm{~T}^{*} \mathrm{~A}^{*} \mathrm{C}^{*} \mathrm{C}^{*} \mathrm{C}^{*} \mathrm{~A}^{*} \mathrm{~T}^{*} \mathrm{C}^{*} \mathrm{G}^{*} \mathrm{~A}^{*} \mathrm{C}^{*} \mathrm{C}^{*} \mathrm{~A}^{*} \mathrm{~T}^{*} \\
\mathrm{C}^{*} \mathrm{~A}^{*} \mathrm{G}^{*} \mathrm{~T}^{*} \mathrm{~T}^{*} \mathrm{~T}^{*} \mathrm{C}^{*} \mathrm{~A}^{*} \mathrm{C}^{*} \mathrm{~A}^{*} \mathrm{G}^{*} \mathrm{~A}^{*} \mathrm{C}^{*}-3\end{array}$ \\
\hline $\mathbf{S}_{2}$ & $\begin{array}{c}\text { 5'-FAM-T*G*A* } \mathrm{C}^{*} \mathrm{~T}^{*} \mathrm{G}^{*} \mathrm{~T}^{*} \mathrm{~T}^{*} \mathrm{rA} \mathrm{A}^{*} \mathrm{G}^{*} \mathrm{G}^{*} \mathrm{~A}^{*} \mathrm{~A}^{*} \mathrm{~T}^{*} \mathrm{G}^{*} \\
\mathrm{~A}^{*} \mathrm{C}^{*} \text {-BHQ1-3' }\end{array}$ \\
\hline $\mathbf{T}$ & 5'-СТТ CСТ ACA CCC ATC TTA TCA-3' \\
\hline $\mathbf{T}_{1}$ & 5'-CTT CCT ACA CCG ATC TTA TCA-3' \\
\hline $\mathbf{T}_{2}$ & 5'-CTT CCT ACA CCG ATC TTT TCA-3' \\
\hline $\mathbf{T}_{3}$ & 5'-CTT CCA ACA CCG ATC TTT TCA-3' \\
\hline miR-21 & 5'-UAG CUU AUC AGA CUG AUG UUG A-3' \\
\hline $\operatorname{miR-144}$ & 5'-UAC AGU AUA GAU GAU GUA CU-3' \\
\hline let-7a & 5'-UGA GGU AGU AGG UUG UAU AGU U-3' \\
\hline miR-155 & 5'-UUAAUG CUA AUC GUG AUA GGG GU-3' \\
\hline miR-429 & 5'-UAA UAC UGU CUG GUA AAA CCG U-3' \\
\hline anti-miR-21 & 5'-TCA ACA TCA GTC TGA TAA GCT A-3' \\
\hline
\end{tabular}


Supporting Information

Table S2. The mutant sequences of miR-21

\begin{tabular}{cc}
\hline Name & Sequence(5'---3') \\
\hline miR-21-1 & 5'-UAG AUU AUC AGA CUG AUG UUG A-3' \\
miR-21-2 & 5'-UAG CUU UUC AGA UUG AUG UUG A-3' \\
miR-21-3 & 5'-UAG CUU AUU UCA CUG AUG UUG A-3' \\
\hline
\end{tabular}


Supporting Information

Table S3. Comparison of different enzyme-free methods for microRNA detection.

\begin{tabular}{|c|c|c|c|}
\hline System & $\begin{array}{l}\text { Sensing time } \\
\text { (h) }\end{array}$ & $\begin{array}{l}\text { Sensitivity } \\
\text { (M) }\end{array}$ & Ref. \\
\hline $\begin{array}{l}\text { Catalytic molecular imaging of } \\
\text { microRNA in living cells by } \\
\text { DNA-programmed nanoparticle } \\
\text { disassembly }\end{array}$ & 6 & $4.56 \times 10^{-12}$ & [1] \\
\hline $\begin{array}{l}\text { Localized catalytic hairpin assembly } \\
\text { reaction for microRNA imaging in live } \\
\text { cells }\end{array}$ & 1 & $2.0 \times 10^{-12}$ & [2] \\
\hline $\begin{array}{c}\text { Cascade circuits on self-assembled } \\
\text { DNA polymers for targeted RNA } \\
\text { imaging in vivo }\end{array}$ & 1 & $3.9 \times 10^{-12}$ & [3] \\
\hline $\begin{array}{l}\text { RNA imaging in living mice enabled by } \\
\text { an in vivo hybridization chain reaction } \\
\text { circuit with a tripartite DNA probe }\end{array}$ & 3 & $8 \times 10^{-13}$ & [4] \\
\hline $\begin{array}{l}\text { Intracellular nonenzymatic in situ } \\
\text { growth of three-dimensional DNA } \\
\text { nanostructures for imaging specific } \\
\text { biomolecules in living cells }\end{array}$ & 2 & $1.4 \times 10^{-12}$ & [5] \\
\hline $\begin{array}{l}\text { A deoxyribozyme-initiated self-catalytic } \\
\text { DNA machine for amplified live-cell } \\
\text { imaging of microRNA }\end{array}$ & 5 & $3 \times 10^{-13}$ & This work \\
\hline
\end{tabular}




\section{Supporting Information}

\section{Schematic illustration of the CSA process}

As illustrated in Figure S1, in the absence of the DNA target, the three hairpin probes, namely $\mathbf{H}_{1}, \mathbf{H}_{2}$ and $\mathbf{H}_{3}$ coexist metastable. After introducing the target DNA $\mathbf{T}$, the toehold region $\mathrm{c}^{*}$ of $\mathbf{H}_{\mathbf{1}}$ first binds to the target to yield $\mathbf{T}-\mathbf{H}_{\mathbf{1}}$. Subsequently, the newly exposed sticky end a of $\mathbf{H}_{\mathbf{1}}$ further hybridizes with the toehold $\mathrm{a}^{*}$ of $\mathbf{H}_{\mathbf{2}}$, forming conjugate $\mathbf{H}_{1}-\mathbf{H}_{2}-\mathbf{T}$. The newly exposed region $\mathrm{d}^{*}$ of $\mathbf{H}_{2}$ then binds to the region $\mathrm{d}$ of $\mathbf{H}_{3}$, leading to target replacement through DNA branch migration and the formation of the Y-shaped DNA. Consequently, the released $\mathbf{T}$ continues to induce the next circle of the CSA reaction.

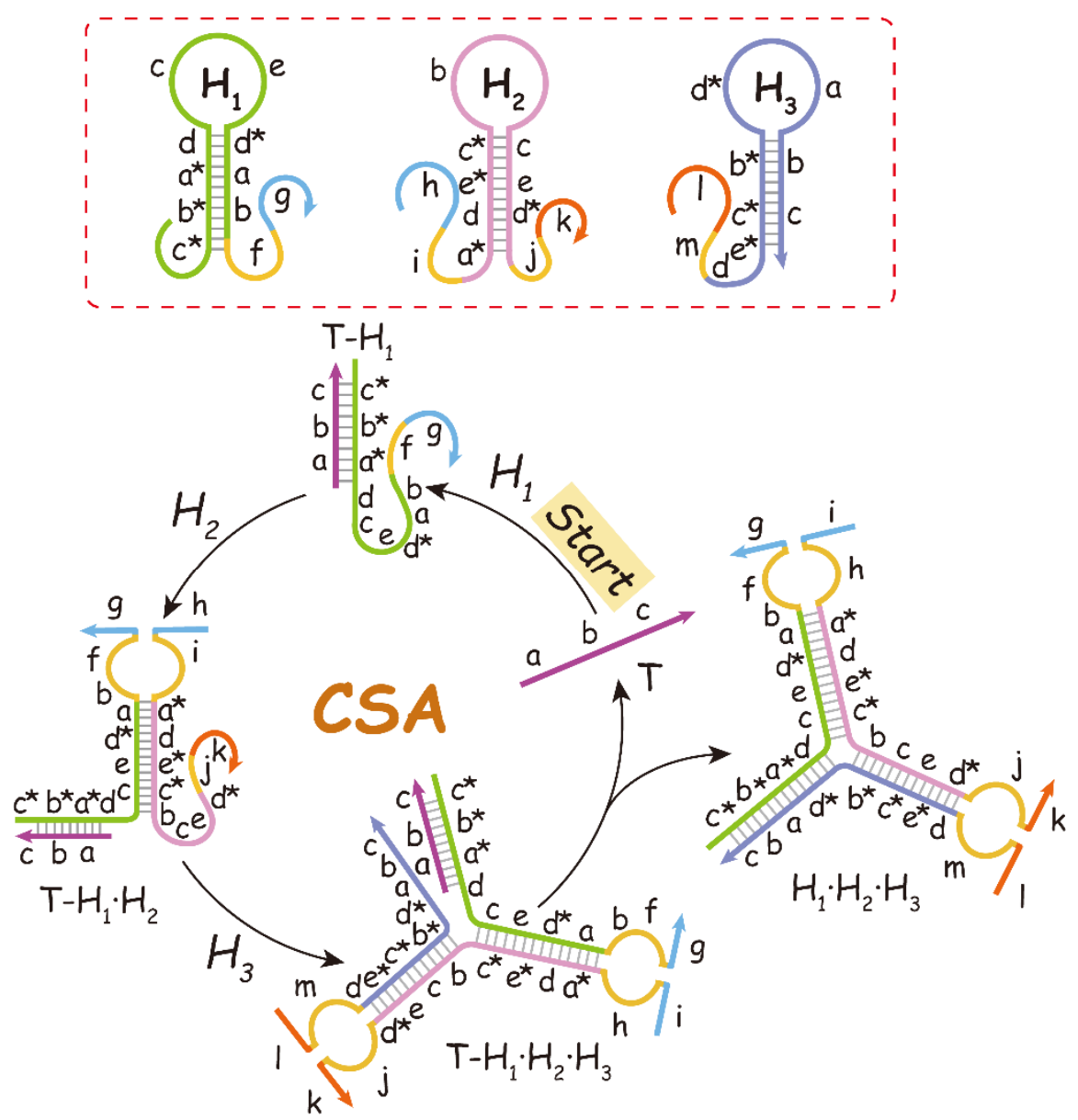

Figure S1. The detailed assembly process of Y-shaped DNA machine. 


\section{Supporting Information}

\section{Optimization of $\mathbf{H}_{2}$}

To establish an efficient signal amplification sensing platform as illustrated in Scheme 1, the three hairpin probes $\mathbf{H}_{1}, \mathbf{H}_{2}$, and $\mathbf{H}_{3}$ that make up the CSA reaction system should satisfy two prerequisites: (1) $\mathbf{H}_{1}, \mathbf{H}_{2}$, and $\mathbf{H}_{3}$ should remained adequately closed in the absence of the trigger (T) to avoid the undesired background signal; (2) $\mathbf{H}_{1}, \mathbf{H}_{2}$, and $\mathbf{H}_{3}$ should be metastable with a limited free energy of secondary structure that enable $\mathbf{H}_{\mathbf{1}}$ can be opened by the trigger $(\mathbf{T})$ and the subsequent cross-opening of all the hairpins. The simulated secondary structures of the three hairpins were shown in Figure S2A, the free energy of $\mathbf{H}_{2}\left(\mathbf{H}_{2 c}\right)$ secondary structure that we initially used is the highest, implying $\mathbf{H}_{2}$ may be too stable to be opened up by $\mathbf{H}_{1}$, thus slowing down the reaction rate. Therefore, we optimized $\mathbf{H}_{2}$ to promote the reaction rate. As shown in Figure S2B, the sensing system with the $\mathbf{H}_{\mathbf{2}}$ showed a higher $\mathrm{S} / \mathrm{N}$ ratio. Therefore, we selected $\mathbf{H}_{\mathbf{2} \mathbf{a}}$ for the follow-up experiments.
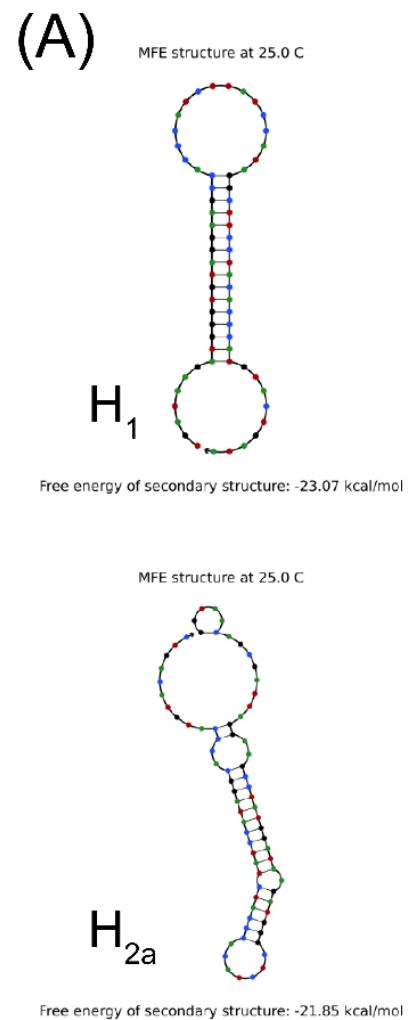
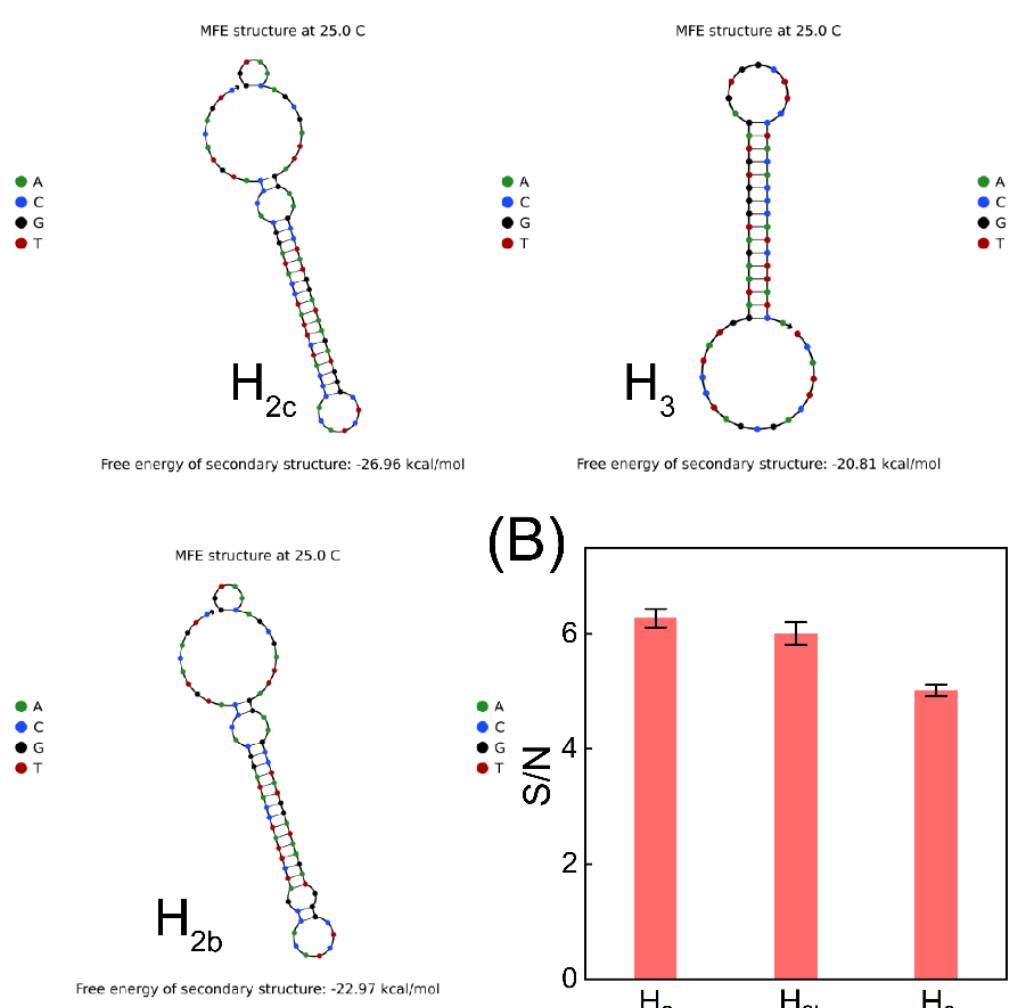

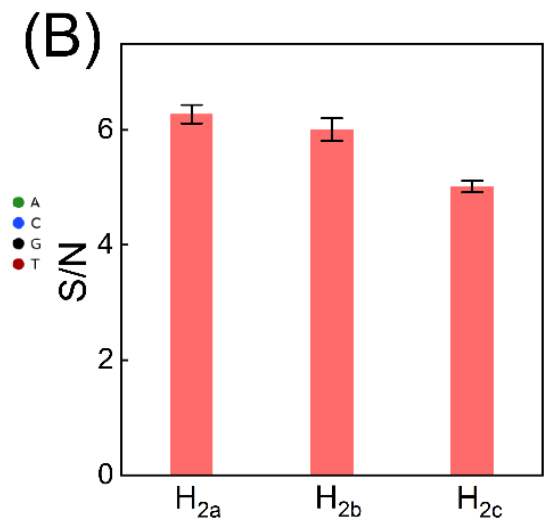

Figure S2. (A) The theoretically simulated secondary structures of all the five hairpins in the SDA sensing system using NUPACK. (B) The signal-to-noise ratio $(\mathrm{S} / \mathrm{N})$ of the SDA sensing system with different $\mathbf{H}_{2}$. Error bars were derived from three parallel experiments. 


\section{Supporting Information}

\section{Optimization of the reaction buffer}

The salt concentrations of reaction buffer impact a lot on the stability of hairpins and DNA double-strand structures, and $\mathrm{Mg}^{2+}$-ion concentration impacts greatly on the activity of DNAzymes because the formed Y-shaped DNA contains two $\mathrm{Mg}^{2+}$-ion-dependent DNAzymes, in turn affecting the signal-to-noise( $\left.\mathrm{S} / \mathrm{N}\right)$ ratio of the sensing system. Here we investigated the effects of salt concentrations of reaction buffer on the $\mathrm{S} / \mathrm{N}$ ratio using different $\mathrm{MgCl}_{2}$ concentrations $(50,100$ and $150 \mathrm{mM}$ ) in $10 \mathrm{mM}$ HEPES buffer. As can be seen from Figure S3, the HEPES buffer containing $1 \mathrm{M} \mathrm{NaCl}$ and $100 \mathrm{mM} \mathrm{MgCl} 2$ revealed a higher $\mathrm{S} / \mathrm{N}$ ratio. Therefore, we selected the HEPES buffer containing $1 \mathrm{M} \mathrm{NaCl}$ and $100 \mathrm{mM} \mathrm{MgCl}_{2}$ as the optimized reaction buffer for the follow-up experiments.

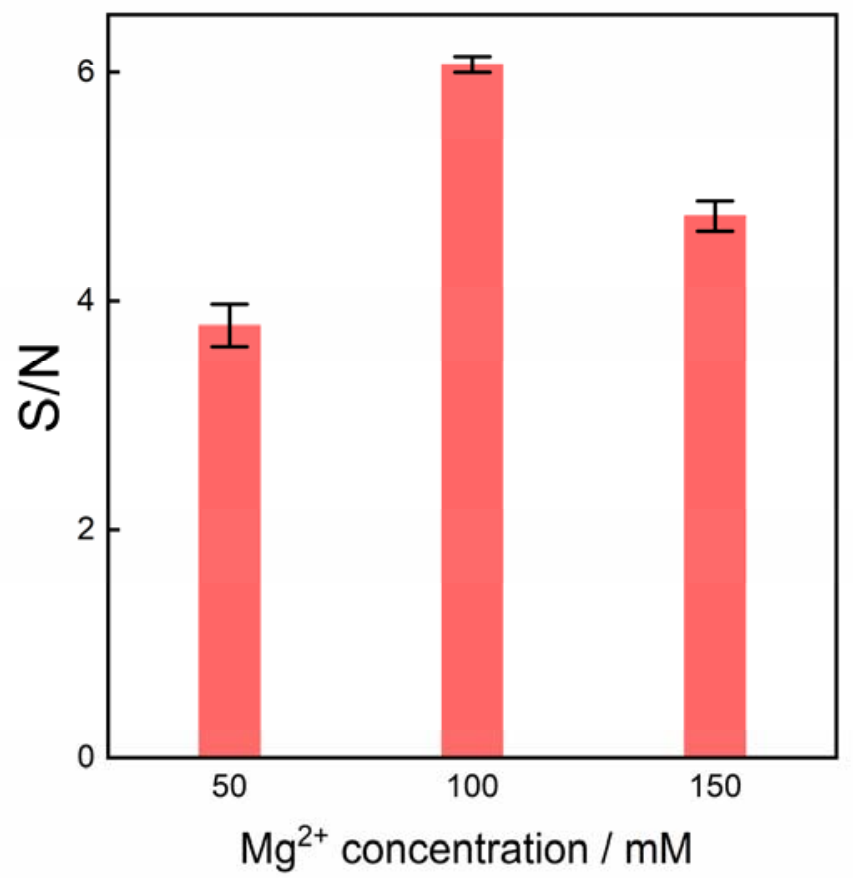

Figure S3. The signal-to-noise ratio $(\mathrm{S} / \mathrm{N})$ of the SDA sensing system in reaction buffer (10 mM HEPES, $1 \mathrm{M} \mathrm{NaCl}$, $\mathrm{pH}$ 7.2) containing different $\mathrm{MgCl}_{2}$ concentrations $(50,100$ and $150 \mathrm{mM})$. Error bars were derived from three parallel experiments. 


\section{Supporting Information}

\section{Optimization of the reaction temperature}

The reaction temperature is of great importance to the hybridization and stability of DNA duplex, thus affecting the sensing performance of the SDA sensing system. Thus, we study the effects of the varied reaction temperature $\left(25^{\circ} \mathrm{C}, 30^{\circ} \mathrm{C}, 37^{\circ} \mathrm{C}\right)$ on the $\mathrm{S} / \mathrm{N}$ ratio of the SDA sensing system. As shown in Figure S4, the SDA sensing system showed a higher $\mathrm{S} / \mathrm{N}$ ratio at $25{ }^{\circ} \mathrm{C}$, therefore we selected $25{ }^{\circ} \mathrm{C}$ as the optimized reaction temperature for the following experiments.

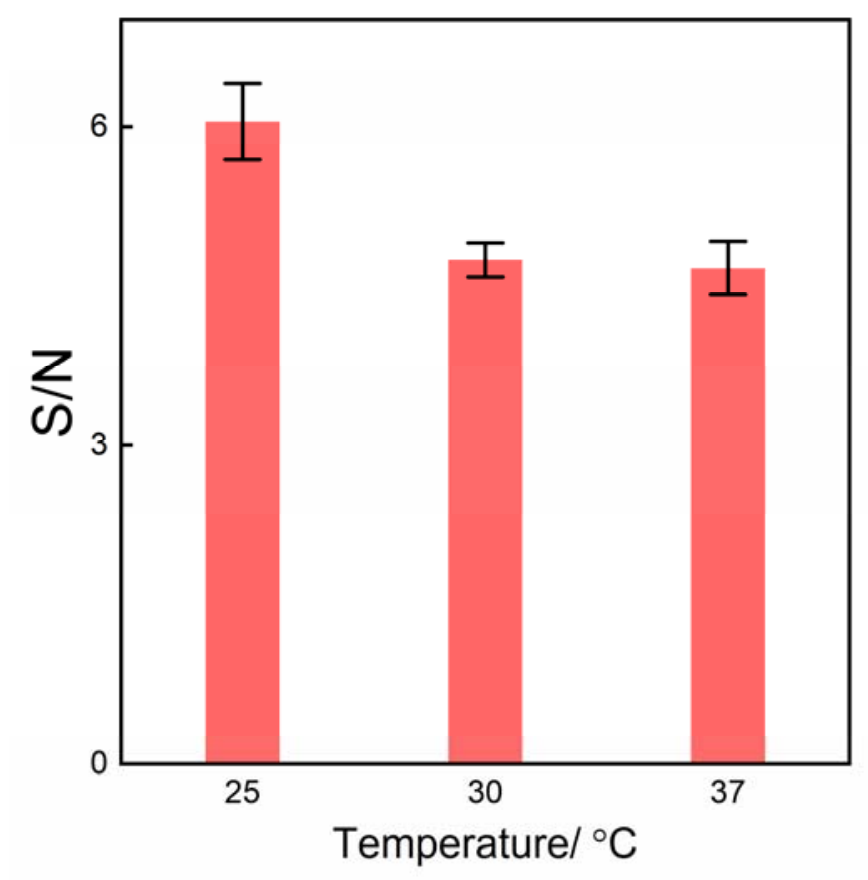

Figure S4. The signal-to-noise ratio $(\mathrm{S} / \mathrm{N})$ of the SDA sensing system implemented in different temperature: $25^{\circ} \mathrm{C}, 30^{\circ} \mathrm{C}$ and $37^{\circ} \mathrm{C}$. Error bars were derived from three parallel experiments. 


\section{Supporting Information}

\section{Optimization of the substrate to the blocker $\left(\mathrm{S}_{1} / \mathrm{L}\right)$ ratio}

In the SDA sensing system, DNA strand $\mathbf{L}$ is used to impede the signal leakage through hybridizing the substrate strand $\mathbf{S}_{\mathbf{1}}$ containing the analogous trigger sequence. Nevertheless, excess $\mathbf{L}$ can bind to the free trigger $\mathbf{T}$ to hinder the rational CSA reaction. As a result, we optimized the concentration ratio of $\mathbf{S}_{\mathbf{1}}$ to $\mathbf{L}$. The result in Figure S5 indicated that a higher $\mathrm{S} / \mathrm{N}$ ratio in the SDA sensing system with a $\mathbf{S}_{\mathbf{1}}$ to $\mathbf{L}$ of $1: 1.1$.

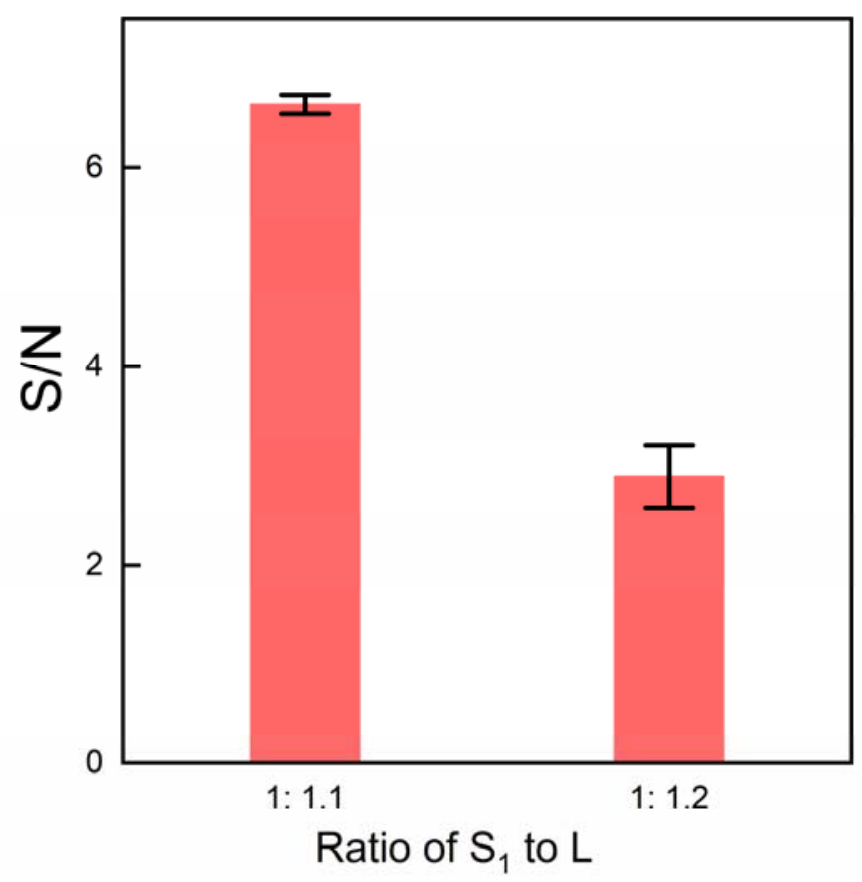

Figure S5. The signal-to-noise ratio $(\mathrm{S} / \mathrm{N})$ of the SDA sensing system with different ratios of $\mathbf{S}_{\mathbf{1}}$ to $\mathbf{L}$. Error bars were derived from three parallel experiments. 


\section{Supporting Information}

\section{Sensitivity of the n-SDA sensing system}

The n-SDA sensing system was applied for analyzing different concentrations of the target $\mathbf{T}$, by recording the fluorescence spectra after a fixed time interval of $5 \mathrm{~h}$ (Figure S6). An increase of fluorescence intensities was observed as the concentration of target increased, originating from the CSA reaction (Figure S6(A)). From the derived calibration curve (Figure S6(B)), the detection limit was calculated to be 0.9 $\mathrm{nM}$ for the n-SDA sensing strategy.

(A)

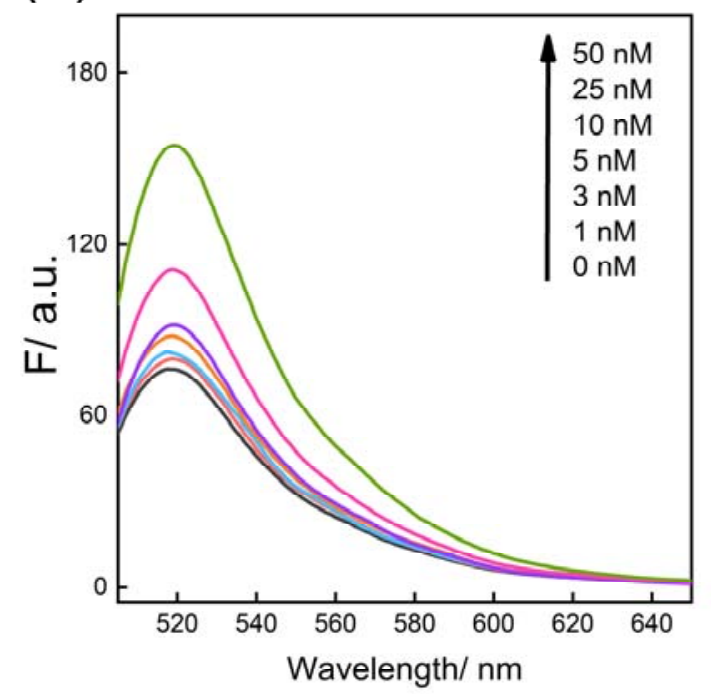

(B)

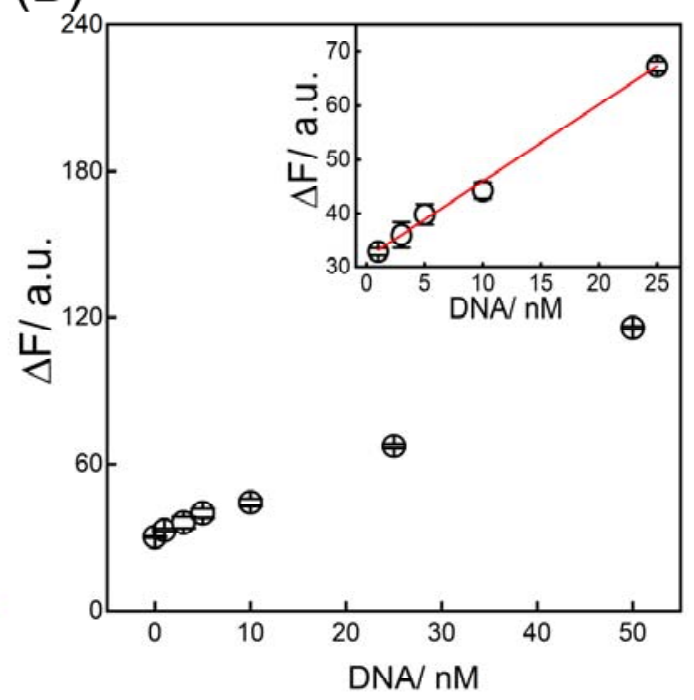

Figure S6. (A) Fluorescence spectra of the n-SDA sensing system triggered by various concentrations of the DNA target. (B) The corresponding calibration curve as indicated by the fluorescence intensity change as a function of the DNA target concentration. Inset: resulting linear calibration curve of Figure S6B. Error bars were derived from three parallel experiments. 


\section{Supporting Information}

\section{Selectivity of the SDA sensing system}

The selectivity of the SDA sensing system was demonstrated by analyzing target $\mathbf{T}$ and its one-, two-, and three-nucleotide-mutant analytes termed as $\mathbf{T}_{\mathbf{1}}, \mathbf{T}_{\mathbf{2}}, \mathbf{T}_{\mathbf{3}}$, respectively. As displayed in Figure S7, the target-treated SDA sensing system exhibits a much higher fluorescence signal than that with $\mathbf{T}_{\mathbf{1}}, \mathbf{T}_{\mathbf{2}}$, and $\mathbf{T}_{\mathbf{3}}$, indicating the excellent selectivity of the present SDA sensing system.

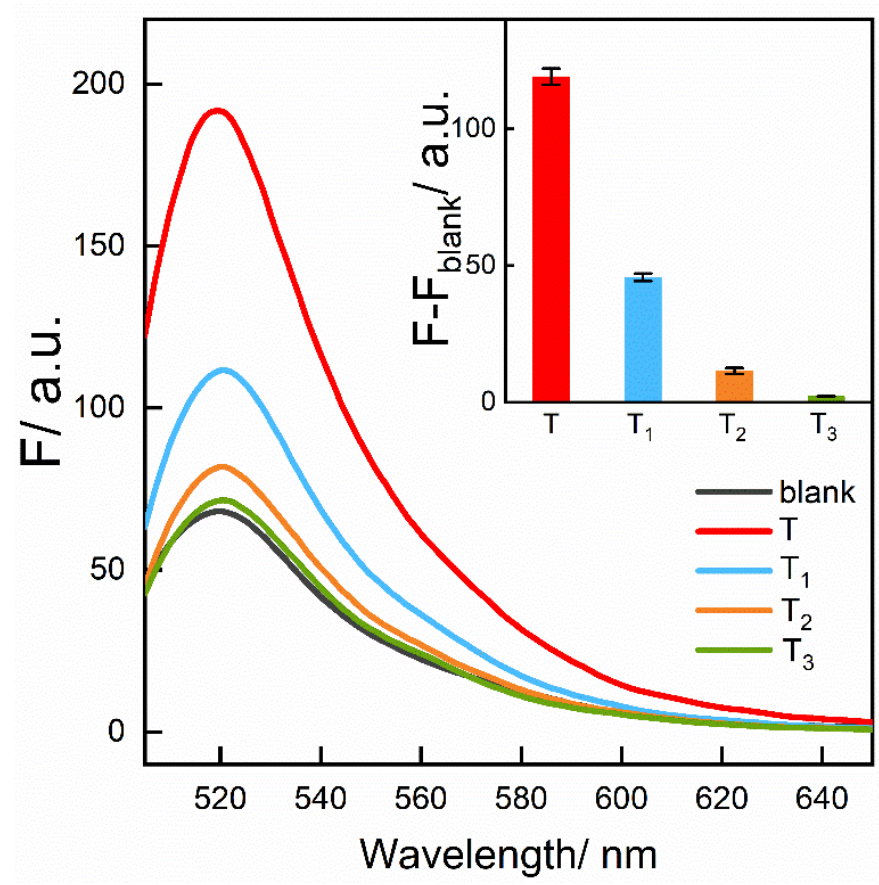

Figure S7. Fluorescence spectra of the updated the SDA sensing system upon analyzing $10 \mathrm{nM}$ of different analytes: $\mathbf{T}, \mathbf{T}_{\mathbf{1}}, \mathbf{T}_{\mathbf{2}}$, and $\mathbf{T}_{\mathbf{3}}$. Inset is the fluorescence intensity differential at $\lambda=520 \mathrm{~nm}$. Error bars were derived from three parallel experiments. 


\section{Supporting Information}

\section{Schematic illustration of updated miR-21-targeting SDA system}

As illustrated in Figure S8, the assistant hairpin probe $\mathbf{H}_{\mathbf{P}}$ can recognize and hybridize with the miR-21 target, and subsequently exerts toehold-mediated strand displacement reaction to liberated the trigger $\mathbf{T}$. Then, the initiator $\mathbf{T}$ feeds into the SDA sensing system, ultimately achieving a remarkably amplified fluorescence signal.

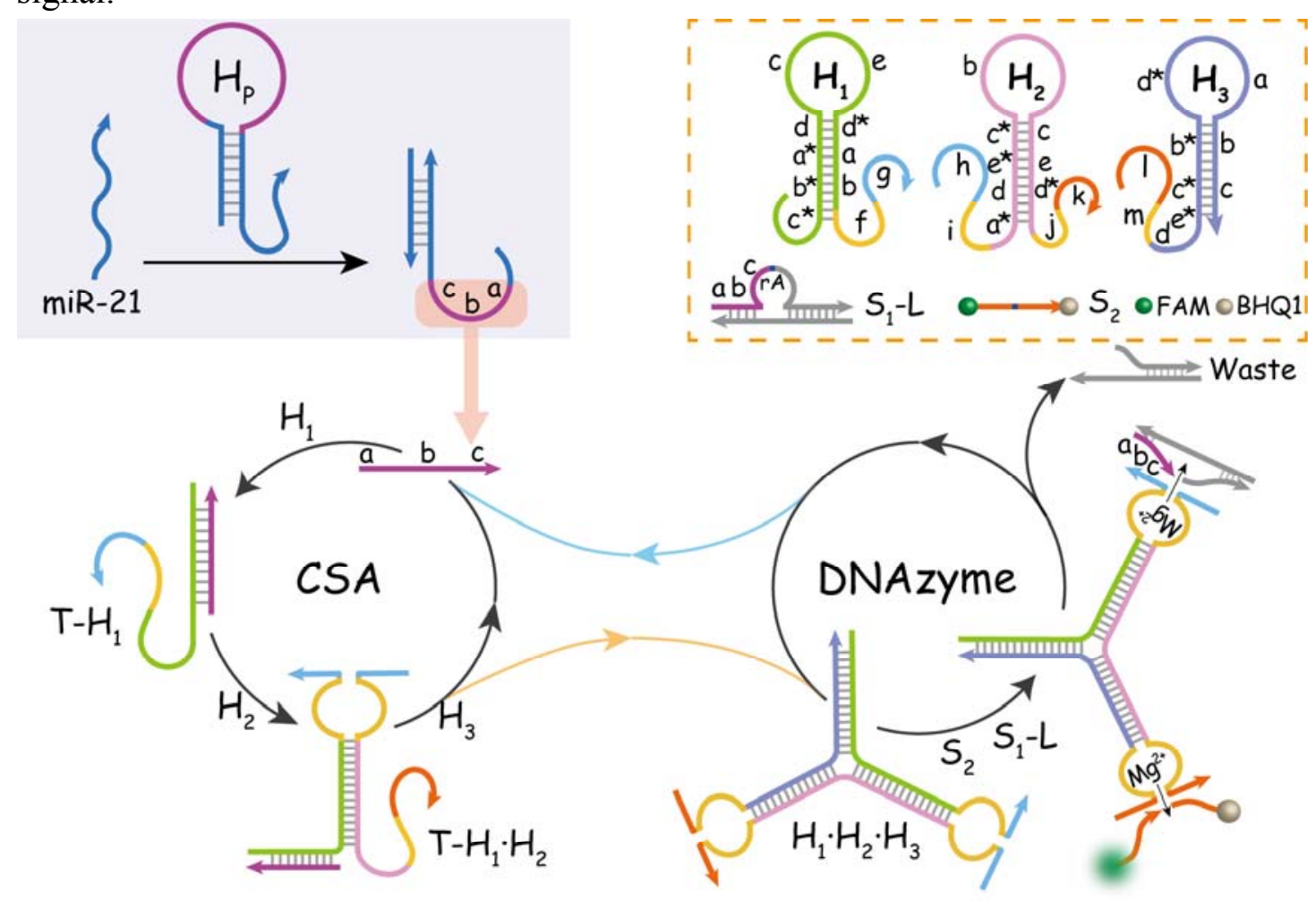

Figure S8. Schematic representation of the updated miR-21-targeting SDA sensing system. 


\section{Supporting Information}

\section{Optimization of the auxiliary hairpin probe}

The versatile SDA sensing system can be converted into a miR-21 sensing system by introducing a helper hairpin probe named $\mathbf{H}_{\mathbf{P}}$, which can be opened up by miR-21, exposing the analogous sequence of trigger $\mathbf{T}$ embedded in $\mathbf{H}_{\mathbf{P}}$. The concentration of $\mathbf{H}_{\mathbf{P}}$ affects the detection performance of the sensing system, therefore we optimized the concentration of $\mathbf{H}_{\mathbf{P}}$. As shown in Figure S9A, the SDA sensing system with a $\mathbf{H}_{\mathbf{P}}$ concentration of $50 \mathrm{nM}$ showed a higher $\mathrm{S} / \mathrm{N}$ ratio, which was selected as the optimized condition for the following miR-21 detection. After optimization, the background noise showed no significant difference with and without $\mathbf{H}_{\mathbf{P}}$ participation (Figure S9B).
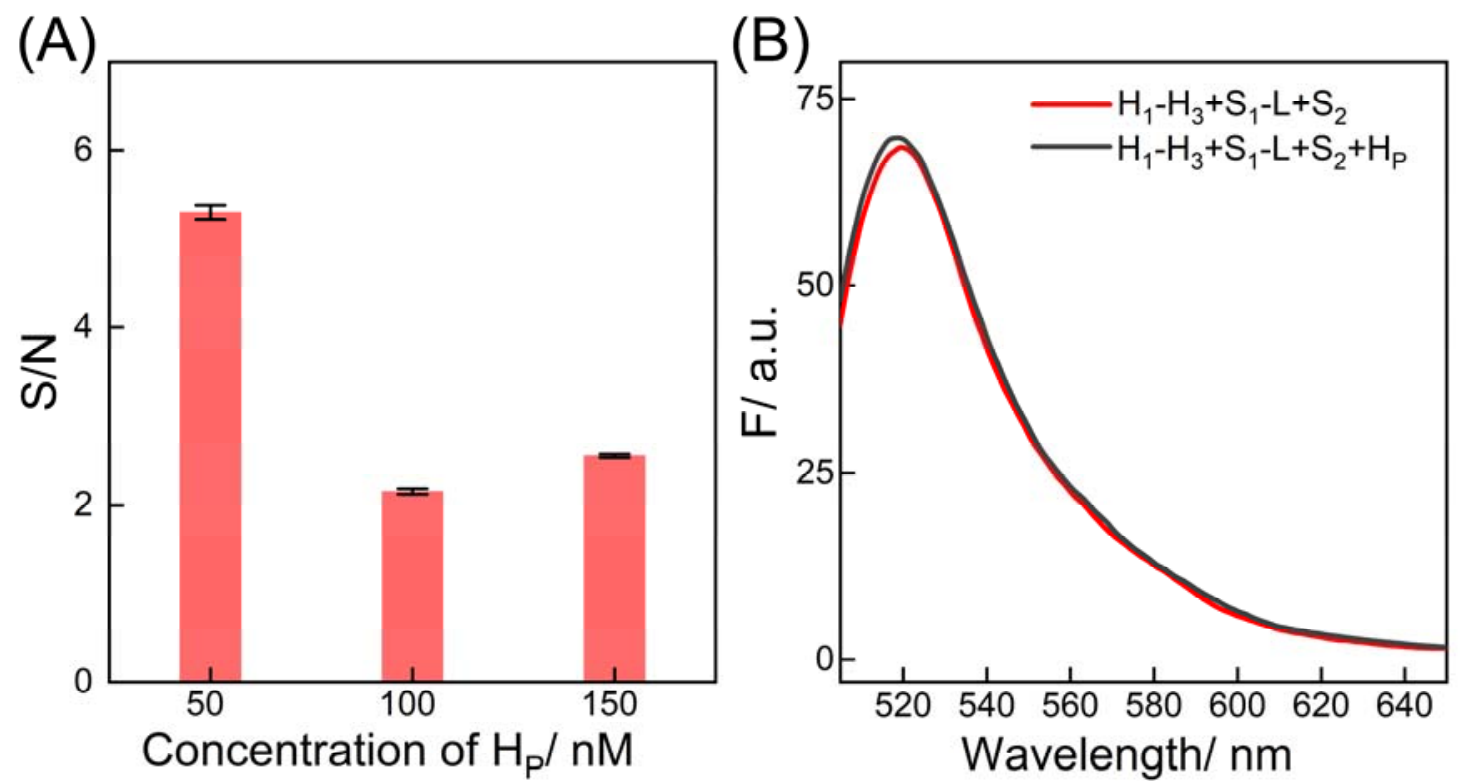

Figure S9. (A) The signal-to-noise ratio $(\mathrm{S} / \mathrm{N})$ of the updated miR-21-senisng SDA system after introducing different concentrations of $\mathbf{H}_{\mathbf{P}}$. (B) The background noise comparison of T-targeting SDA and miR-21-targeting SDA sensing systems after optimization of $\mathbf{H}_{\mathbf{P}}$. Error bars were derived from three parallel experiments. 


\section{Supporting Information}

\section{Specificity of updated miR-21-targeting SDA sensing system}

The specificity of the miR-21-analyzing system was further explored by using one-, two-, and three-base mutant miR-21 interfering sequences (nominated as miR-21-1, miR-21-2, and miR-21-3, respectively). As shown in Figure S10, as compared to the complementary miR-21 analyte (curve a), the one-base mutant analyte (miR-21-1) shows a dramatically decreased fluorescence transduction (curve b). The fluorescence intensity exhibited little enhancement for other mutant initiators (two-based mutant miR-21-2 and three-base mutant miR-21-3), implying that the SDA sensing system affords high specificity for analyzing miR-21 with single-base mutation discrimination. The mutant sequences of miR-21 are listed in the Table S3.

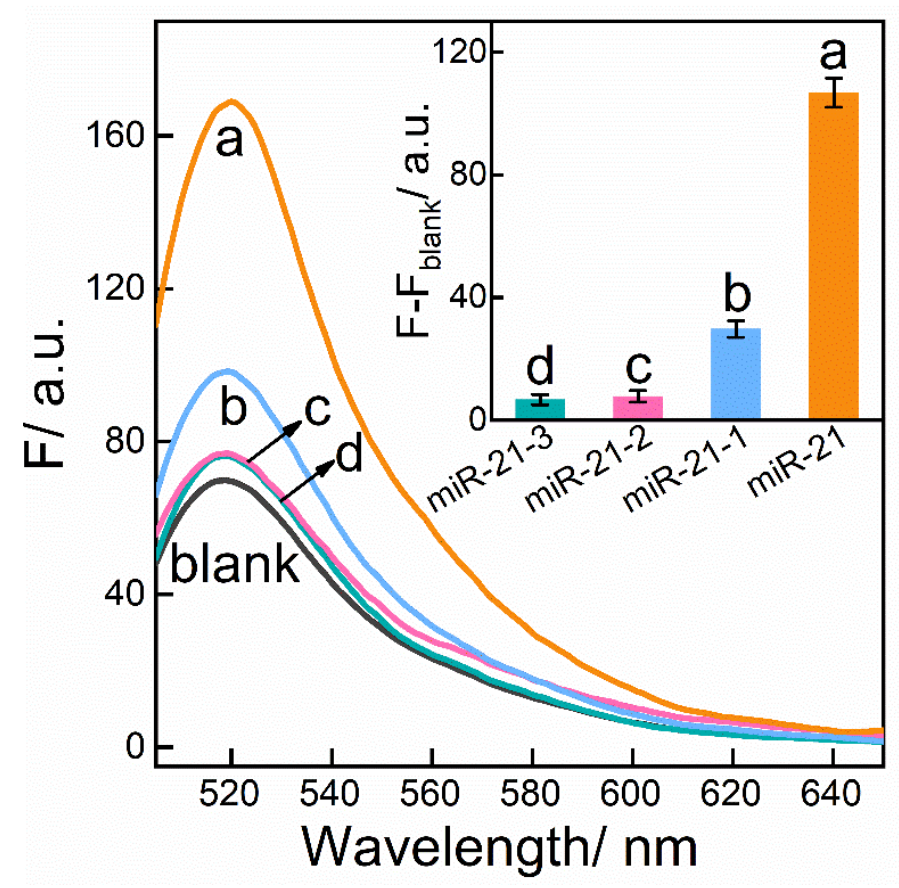

Figure S10. Fluorescence spectra of the updated miR-21-targeting SDA sensing system upon analyzing $10 \mathrm{nM}$ of different targets: (a) miR-21, (b) miR-21-1, (c) miR-21-2, and (d) miR-21-3. Inset is the fluorescence intensity differential at $\lambda=520$ nm. Error bars were derived from three parallel experiments. 


\section{Supporting Information}

\section{Performance of the SDA sensing system in serum samples}

The stability of the updated sensing system is crucial for monitoring intracellular miRNA in complex biological environment. Diluted serums were thus used as reaction buffers to investigate the stability of this reconfigured system. The fluorescence intensity of the updated system in $0 \%, 5 \%$ and $10 \%$ serum buffers for miR-21 detection were recorded. As shown in Figure S11, the performance of the updated SDA sensing system in dilute serums was almost a little higher than that in buffer while remaining an almost same fluorescence change, indicating that the system possessed moderate resistance to nuclease and kept stable in biological environment.

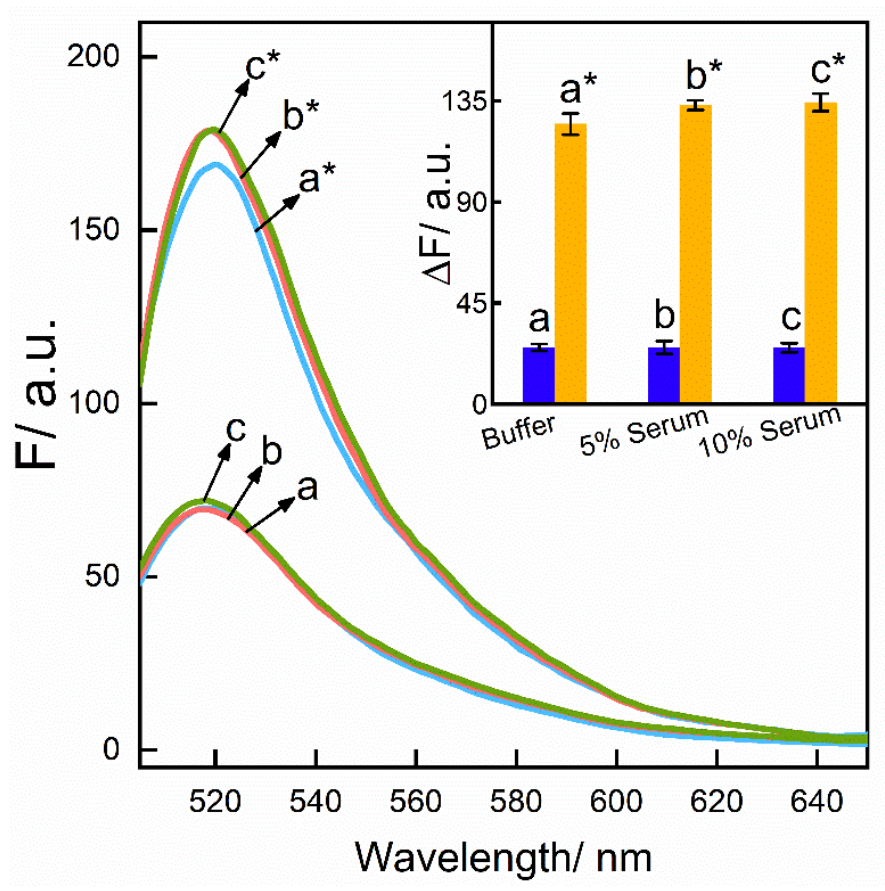

Figure S11. Fluorescence spectra of the updated miR-21-sensing system in different reaction buffers. Inset graph: Fluorescence intensity differentials of the miR-21-sensing system in the absence $(a, b, c)$ and in the presence $\left(a^{*}, b^{*}, c^{*}\right)$ of miR-21 under different reaction buffers. Error bars were derived from three parallel experiments. 


\section{Supporting Information}

\section{Incubation time optimization for intracellular miR-21 imaging}

To study the incubation kinetics of probes in cells, MCF-7 cells were allowed to incubate with the SDA sensing system for different time-intervals $(0-4 \mathrm{~h})$. The fluorescence of cells was quantified by flow cytometry. The result in Figure $\mathbf{S 1 2}$ suggests that fluorescence signals in MCF-7 cells increased with time, where the fluorescence intensity reached a plateau when the incubation time was 3 hours. Thus, we chose an incubation time of 3 hours as the optimized incubation time for following intracellular imaging of miR-21.

(A)

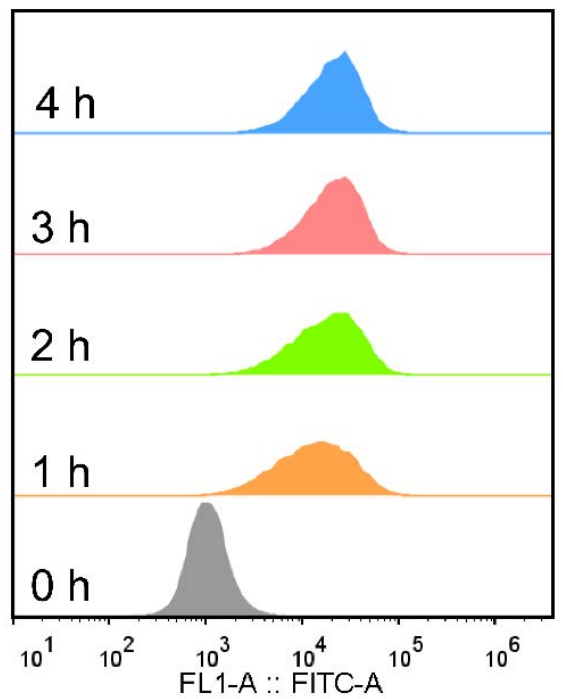

(B)

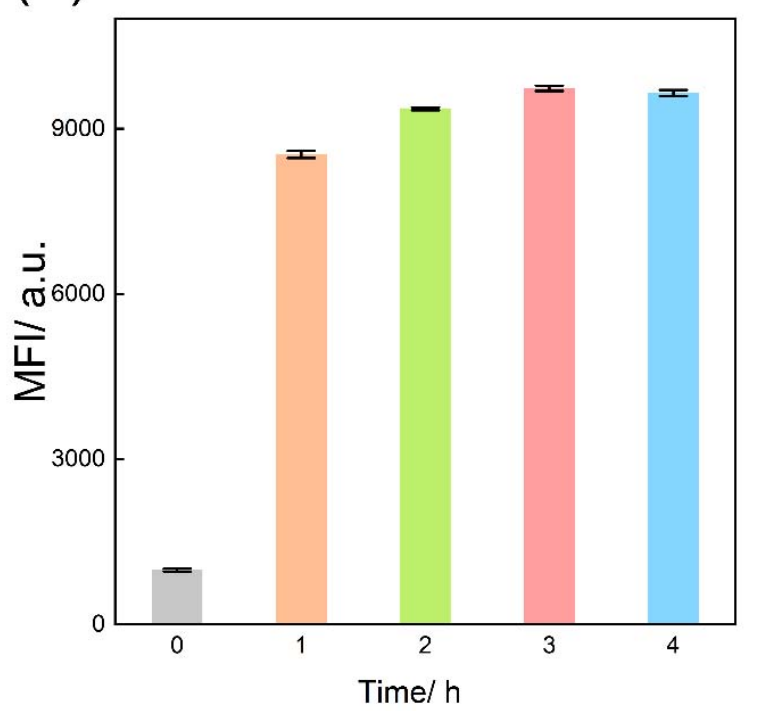

Figure S12. (A) Flow cytometry analysis and (B) the corresponding mean fluorescence intensity (MFI) of MCF-7 cells treated with the SDA sensing system for different time-intervals. Error bars were derived from three parallel experiments. 


\section{Supporting Information}

\section{Flow cytometry of MCF-7 cells treated with the SDA and the n-SDA system}

To quantitative the fluorescence signals of the SDA and the n-SDA systems in living cells, flow cytometry analysis was performed (Figure S13). In contrast with the n-SDA sensing system, the SDA sensing system-transfected MCF-7 cells showed a higher fluorescence signal, demonstrating the better signal amplification ability of the SDA system, which is in good accordance with the confocal microscopy results.

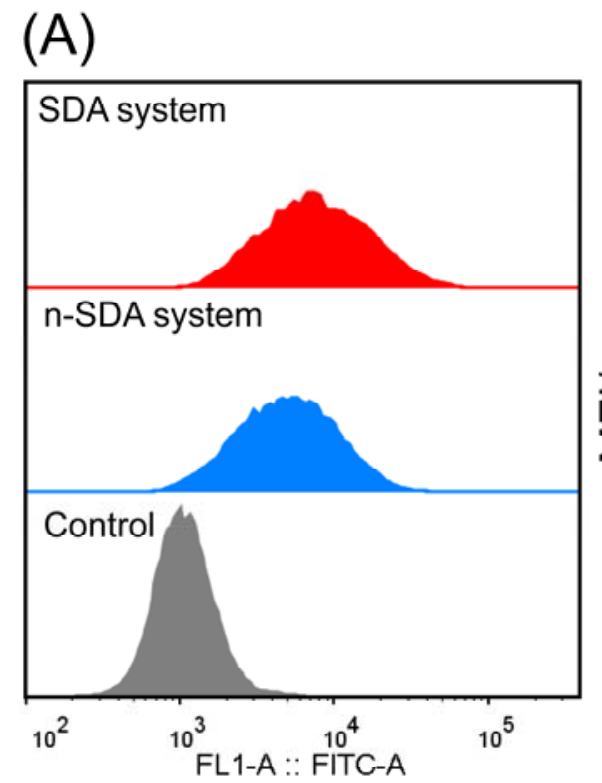

(B)

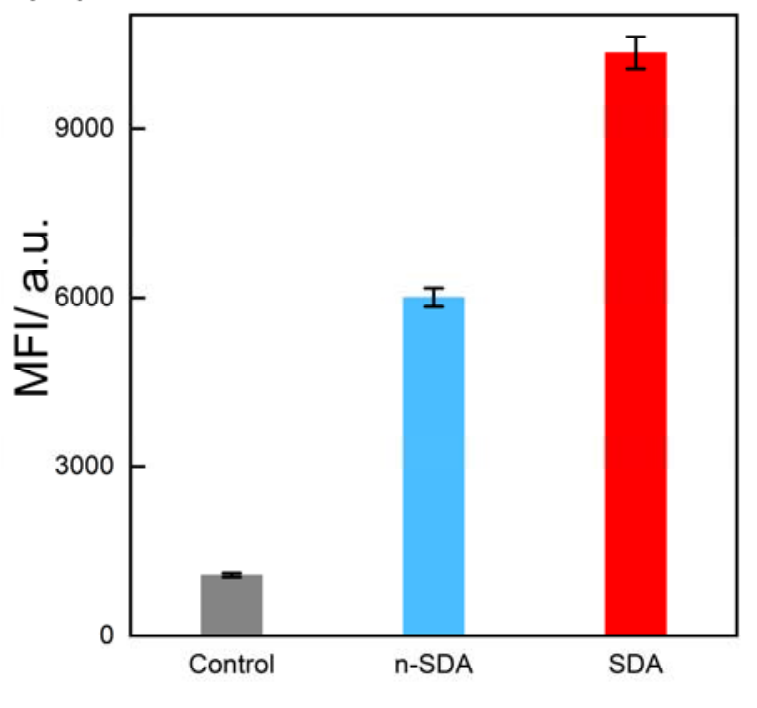

Figure S13. (A) Flow cytometry analysis and (B) the corresponding mean fluorescence intensity (MFI) of MCF-7 cells treated with the SDA and the n-SDA sensing systems for $3 \mathrm{~h}$ at $37{ }^{\circ} \mathrm{C}$. Error bars were derived from three parallel experiments. 


\section{Supporting Information}

\section{References}

(1) He, X.; Zeng, T.; Li, Z.; Wang, G.; Ma, N. Catalytic molecular imaging of microRNA in living cells by DNA-programmed nanoparticle disassembly. Angew. Chem. 2016, 128, 3125-3128.

(2) Wei, Q.; Huang, J.; Li, J.; Wang, J.; Yang, X.; Liu, J.; Wang, K. A DNA nanowire based localized catalytic hairpin assembly reaction for microRNA imaging in live cells. Chem. Sci. 2018, 9, 7802-7808.

(3) Zhu, X.; Qu, B.; Ying, Z.; Liu, J.; Wu, Z.; Yu, Q.; Jiang, J. Cascade circuits on self-assembled DNA polymers for targeted RNA imaging in vivo. Anal. Chem. 2020, 92, 15953-15958.

(4) Wu, H.; Chen, T.; Wang, X.; Ke, Y.; Jiang, J. RNA imaging in living mice enabled by an in vivo hybridization chain reaction circuit with a tripartite DNA probe. Chem. Sci. 2020, 11, 62-69.

(5) Liu, R.; Zhang, S.; Zheng, T.; Chen, Y.; Wu, J.; Wu, Z. Intracellular nonenzymatic in situ growth of three-dimensional DNA nanostructures for imaging specific biomolecules in living cells. ACS Nano 2020, 14, 9572-9584. 